\section{Commentary: Potts palliation for pulmonary hypertension: What's next?}

\author{
Emre Belli, MD
}

Pulmonary hypertension (PH) in children, adolescents, and young adults is a rare but complex clinical condition. Despite significant improvements in medical therapy, outcomes remain poor. Lung transplantation was the only surgical therapeutic option before we proposed the Potts alternative for medication-refractory patients as a novel palliative approach. ${ }^{1,2}$ The initial experience included exclusively patients presenting with idiopathic $\mathrm{PH}$ between ages 3 and 15 years. Then, percutaneous transcatheter Potts was also performed in 5 patients. In addition, 1 patient benefited from a surgical unidirectional valved Potts anastomosis. ${ }^{3}$ All procedures were performed without cardiopulmonary bypass or extracorporeal membrane oxygenation support. The outcomes demonstrated the technical safety and, despite 3 out of 24 with early mortality, no late mortality, improved clinical condition, and functional capacity, or left ventricular diastolic and right ventricular systolic function. One child underwent double lung transplantation because of refractory hemoptysis anticipated by percutaneous closure of her Potts shunt performed 6 years earlier.

Lancaster and colleagues ${ }^{4}$ started their Potts palliation program for $\mathrm{PH}$ in 2013. They favorably compared their series with noncontemporary lung transplant patients. Their experience opened 4 new dimensions for Potts in PH settings:

- Potts palliation (other than idiopathic PH) for Eisenmenger and Shone complex patients;

- Emergency Potts in acutely decompensated children;

\footnotetext{
From the Department of Congenital and Pediatric Heart Disease, Marie Lannelongue Hospital, University Paris-Saclay, Le Plessis-Robinson, France.

Disclosures: The author reported no conflicts of interest.

The Journal policy requires editors and reviewers to disclose conflicts of interest and to decline handling or reviewing manuscripts for which they may have a conflict of interest. The editors and reviewers of this article have no conflicts of interest

Received for publication Nov 25, 2020; revisions received Nov 25, 2020; accepted for publication Nov 25, 2020; available ahead of print Dec 5, 2020.

Address for reprints: Emre Belli, MD, Department of Congenital and Pediatric Heart Disease, Marie Lannelongue Hospital, University Paris-Saclay, M3C, GHPSJ, 133 Ave de la Resistance, Le Plessis-Robinson, France (E-mail: emrebel@gmail.com). J Thorac Cardiovasc Surg 2021;161:1152-3

$0022-5223 / \$ 36.00$

Copyright (c) 2020 by The American Association for Thoracic Surgery

https://doi.org/10.1016/j.jtcvs.2020.11.135
}

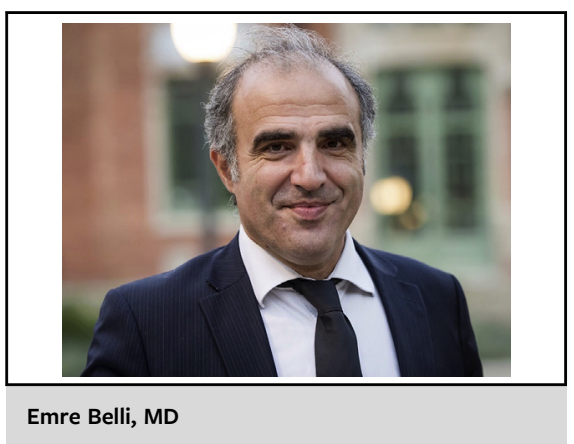

CENTRAL MESSAGE

Potts palliation for $\mathrm{PH}$ in children

has made itself a place in our

therapeutic armamentarium. It

seems to be more appropriate to

concentrate children with $\mathrm{PH}$ in

centers with specific expertise.

- Frequent (or preference for) conduit and also valved conduit Potts anastomosis; and

- Frequent extracorporeal membrane oxygenation/ coronary pulmonary bypass support.

Major complications were not uncommon $(35 \%)$ and their experience discredited the emergency Potts option. They considered Potts palliation as an effective alternative but also a bridge for subsequent lung transplantation by improvement of the patient's clinical condition, and also, despite not being stated in the article, allowing children to reach larger size and thus suitable for adult lung donors, which are by definition more available.

Among the major dangers concerning the efficiency of any particular surgical technique, especially in the case that the later is palliative, seems to be its abuse. Despite small cohorts, Potts palliation affirmed its safety as a lifesaving technique in children with poorly tolerated idiopathic PH. Its application in other etiologic forms of PH must still be considered with caution. And above all, it seems now to be necessary for precisely defining indication criteria and the optimal timing for Potts palliation in children with PH. The application of Potts in the setting of Eisenmenger might justify its use in this particular group of patients, not only after, but also concomitant with, the closure of intracardiac defects?

Potts palliation for $\mathrm{PH}$ in children has made a place for itself in our therapeutic armamentarium. As in cases of any rare diseases and its management, it seems to be more appropriate to concentrate children with $\mathrm{PH}$ in centers with specific expertise. 


\section{References}

1. Blanc J, Vouhe P, Bonnet D. Potts shunt in patients with pulmonary hypertension. N Engl J Med. 2004;350:623.

2. Baruteau AE, Belli E, Boudjemline Y, Laux D, Lévy M, Simonneau G, et al. Palliative Potts shunt for the treatment of children with drug-refractory pulmonary arterial hypertension: updated data from the first 24 patients. Eur J Cardiothorac Surg. 2015;47:e105-10
3. Bui MT, Grollmus O, Ly M, Mandache A, Fadel E, Decante B, et al. Surgica palliation of primary pulmonary arterial hypertension by a unidirectional valved Potts anastomosis in an animal model. J Thorac Cardiovasc Surg. 2011;142: 1223-8.

4. Lancaster TS, Shahanavaz S, Balzer DT, Sweet SC, Grady RM, Eghtesady P. Midterm outcomes of the Potts shunt for pediatric pulmonary hypertension, with comparison to lung transplant. J Thorac Cardiovasc Surg. 2021;161:1139-48.
See Article page 1139.

\section{Commentary: Repair or replace- Potts shunt versus lung transplantation for refractory pediatric pulmonary hypertension}

\author{
Joseph R. Nellis, MD, MBA, ${ }^{\mathrm{a}}$ \\ John C. Haney, MD, MPH, ${ }^{\mathrm{b}}$ and \\ Joseph W. Turek, MD, PhD ${ }^{\mathrm{a}, \mathrm{b}, \mathrm{c}}$
}

Patients presenting with medically refractory pulmonary hypertension are traditionally listed for lung transplantation. Historically, the availability of suitable donor lungs, particularly for pediatric patients, led to long waitlist times and increased morbidity and mortality. Lancaster and colleagues $^{1}$ review their success using Potts shunts as an alternative to lung transplantation in this population over the past 6 years, discuss key learning points, and demonstrate their technique for a valved Potts shunt.

Engines today are commonly built in a V-configuration (eg, V4, V6, V8), wherein an equal number of cylinders are present on either side of an engine block, orientated away from one another like a V. The configuration decreases the length of the engine block relative to an inline

\footnotetext{
From the ${ }^{\mathrm{a}}$ Duke Congenital Heart Surgery Research \& Training Laboratory and ${ }^{\mathrm{b}} \mathrm{Di}$ vision of Thoracic and Cardiovascular Surgery, Duke University, Durham, NC; and 'Duke Children's Pediatric \& Congenital Heart Center, Duke Children's Hospital, Durham, NC.

Disclosures: The authors reported no conflicts of interest.

The Journal policy requires editors and reviewers to disclose conflicts of interest and to decline handling or reviewing manuscripts for which they may have a conflict of interest. The editors and reviewers of this article have no conflicts of interest.

Received for publication Nov 21, 2020; revisions received Nov 21, 2020; accepted for publication Nov 23, 2020; available ahead of print Dec 3, 2020.

Address for reprints: Joseph W. Turek, MD, PhD, Division of Thoracic and Cardiovascular Surgery, Duke University Medical Center, 2301 Erwin Rd, DUMC 3474, Durham, NC 27710 (E-mail: joseph.turek@duke.edu).

J Thorac Cardiovasc Surg 2021;161:1153-4

0022-5223/\$36.00

Copyright (C) 2020 by The American Association for Thoracic Surgery

https://doi.org/10.1016/j.jtcvs.2020.11.129
}

Check for updates

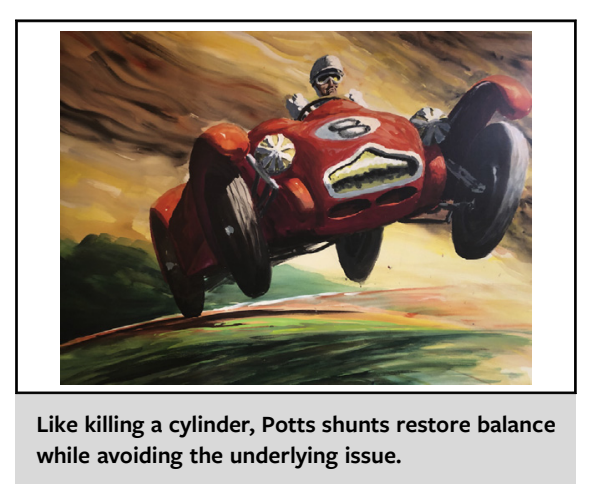

CENTRAL MESSAGE

Potts shunts equilibrate right and

left ventricular pressures to

improve the functional status in

patients with refractory pulmo-

nary hypertension, although

long-term results remain largely

unknown.

configuration, although it requires all cylinders to fire symmetrically for the engine to remain balanced. If a cylinder misfires, or becomes asymmetric, there is a reduction in power, increased noise, and a shutter due to the lack of balance within the engine. If left untreated, this can progress to engine failure. In a majority of cases, this issue can be fixed by replacing a spark plug or gasket. Although in other cases, the cylinder itself is warped and car owners are faced with the decision of repairing the engine block or replacing the engine entirely.

In a similar fashion, patients with refractory pulmonary hypertension develop cardiac dysfunction and activity restriction that can carry fatal long-term consequences unless managed through a Potts shunt or lung transplantation as described by Lancaster and colleagues ${ }^{1}$ in this issue of the Journal. In their retrospective study, the authors compare outcomes for patients historically undergoing lung 